\title{
Is low intensity vibration harmful to the digits?
}

\author{
J VESTBO,' INGE VESTBO,' K-O LARSEN,2 AND S L NIELSEN' \\ From the Department of Clinical Physiology, ${ }^{1}$ Gentofte Hospital, and the Clinic of Occupational Medicine, ${ }^{2}$ \\ Rigshospitalet, Copenhagen, Denmark
}

Numerous articles have described the effects of hand arm vibration, mostly relating high intensity vibration to vibration induced white finger. The effects of low intensity vibration on the circulation and the peripheral nervous system are poorly known. Workers exposed to low intensity vibration have vague and uncharacteristic complaints and the findings are dubious. We have examined three groups exposed to low intensity vibration by measuring the rewarming time after cold provocation; the three groups consisted of crane drivers, motor cycle policemen, and sandblasters.

\section{Material and method}

The blood pressure in the arm was measured by auscultation of the subclavian artery. A cuff around the wrist (width $60 \mathrm{~mm}$ ) was inflated to $300 \mathrm{~mm} \mathrm{Hg}$ and the hand was immersed in water at $10^{\circ} \mathrm{C}$ under stirring for five minutes. After light drying with a towel, fingerclips were placed on the fingertips. The apparatus was started, and the wrist cuff was deflated simultaneously. The temperature of the fingertips was recorded by thermocouples (Analog Devices AD 590) mounted in polyvinyl chloride blocks in the fingerclips and was given every five seconds on the digital display of the apparatus constructed at the Electromedical Laboratory at Herlev Hospital. Pushing the start button activated a timer that measured the time for each finger to reach $24^{\circ} \mathrm{C}$ after a 20 second latent period. After stopping the recording these times were displayed for each finger. If the temperature of the fingers did not reach $24^{\circ} \mathrm{C}$ within 10 minutes the recording was stopped. In both the crane driver and the sandblaster studies the subjects were lying on a couch dressed in outdoor clothes (outdoor temperature $4^{\circ} \mathrm{C}$ ) in a room at $24^{\circ} \mathrm{C}$. In the third study the subjects were lying in a water perfused heating blanket (Heto, Copenhagen).

\section{Results}

The results were in no way unambiguous. The mean rewarming time of subjects exposed to low intensity vibration was higher than that of a control group (table) but with a high degree of overlap.

The complaints from the subjects exposed to low intensity vibration varied from "no symptoms at all" over "intermittent tingling and numbness" to "attacks of dead fingers in the winter time."

\section{Statistics}

The rewarming time of the crane drivers were compared with their control group using a MannWhitney rank sum test for unpaired data.

\section{Discussion}

There is no exposure limit for low intensity vibration; the number of people exposed to light vibration is large and therefore the problem is of great interest. Little has been published; the only certain thing is that low intensity vibration rarely causes vibration induced white finger.' The complaints from

Age and rewarming times for three exposed groups and two control groups

\begin{tabular}{|c|c|c|c|c|c|c|}
\hline & \multicolumn{3}{|c|}{ Age } & \multicolumn{3}{|c|}{ Rewarming times } \\
\hline & No & Mean & Range & Mean & Range & \\
\hline $\begin{array}{l}\text { Crane drivers } \\
\text { Control group } \\
\text { Sandblasters } \\
\text { Motorcycle policemen } \\
\text { Control group }\end{array}$ & $\begin{array}{l}42 \\
21 \\
50 \\
56 \\
50\end{array}$ & $\begin{array}{l}39 \\
39 \\
40 \\
37 \\
37\end{array}$ & $\begin{array}{l}22-58 \\
23-59 \\
20-50 \\
27-60 \\
26-60\end{array}$ & $\begin{array}{l}221 \\
139 \\
218 \\
269 \\
244\end{array}$ & $\begin{array}{l}44-600 \\
32-278 \\
41-413 \\
49-657 \\
43-699\end{array}$ & $0.05<p<0.10$ \\
\hline
\end{tabular}


subjects exposed to low intensity vibration suggest a neurological aetiology. No studies using perception tests or measuring vibration threshold limits in people exposed to low intensity vibration have been published, however. Studies of vibration induced white finger in motor cycle riders ${ }^{23}$ cannot be compared with each other or with our study because of the considerable difference in type of motor cycle or machine.

Measuring rewarming time after cold provocation is a valid method for diagnosing primary and secondary Raynaud's phenomenon, ${ }^{4}$ but the cause of the higher rewarming times in the groups exposed to low intensity vibration is uncertain. Whether it is the result of the effect of vibration on the arterioles or due to disturbances in the microcirculation or thermoreceptors cannot be deduced from the results. Also, the pronounced overlapping of the results (table) indicates that the way the individual handles his work is important, but this cannot be deduced directly either. The high rewarming times in the control group of the motorcycle study are interesting. The only possible explanation for this is the high degree of tension in this group consisting of ordinary policemen without exposure to vibration.

\section{References}

' Brammer AJ. Relations between vibration exposure and the development of the vibration syndrome. In: Brammer AJ, Taylor W, eds. Vibration effects on the hand and arm in industry. New York: Wiley, 1982:283-90.

${ }^{2}$ Bentley S, O'Connor DE, Lord P, Edmonds OP. Vibration white finger in motorcycle speedway riders. In: Brammer AJ, Taylor $\mathrm{W}$, eds. Vibration effects on the hand and arm in industry. New York: Wiley, 1982:189-92.

${ }^{3}$ Harrison RT, Murphy WA. Motorcycle handlebar vibration. In: Brammer AJ, Taylor W, eds. Vibration effects on the hand and arm in industry. New York: Wiley, 1982:239-44.

4 Juul C, Nielsen SL. Locally induced digital vasospasm detected by delayed rewarming in Raynaud's phenomenon of occupational origin. Br J Ind Med 1981;38:87-90.

\section{Correction}

\section{Nasal cancer in the textile and clothing industries (July 1985)}

There was an error in the map printed on page 470 . The correct map is shown below.

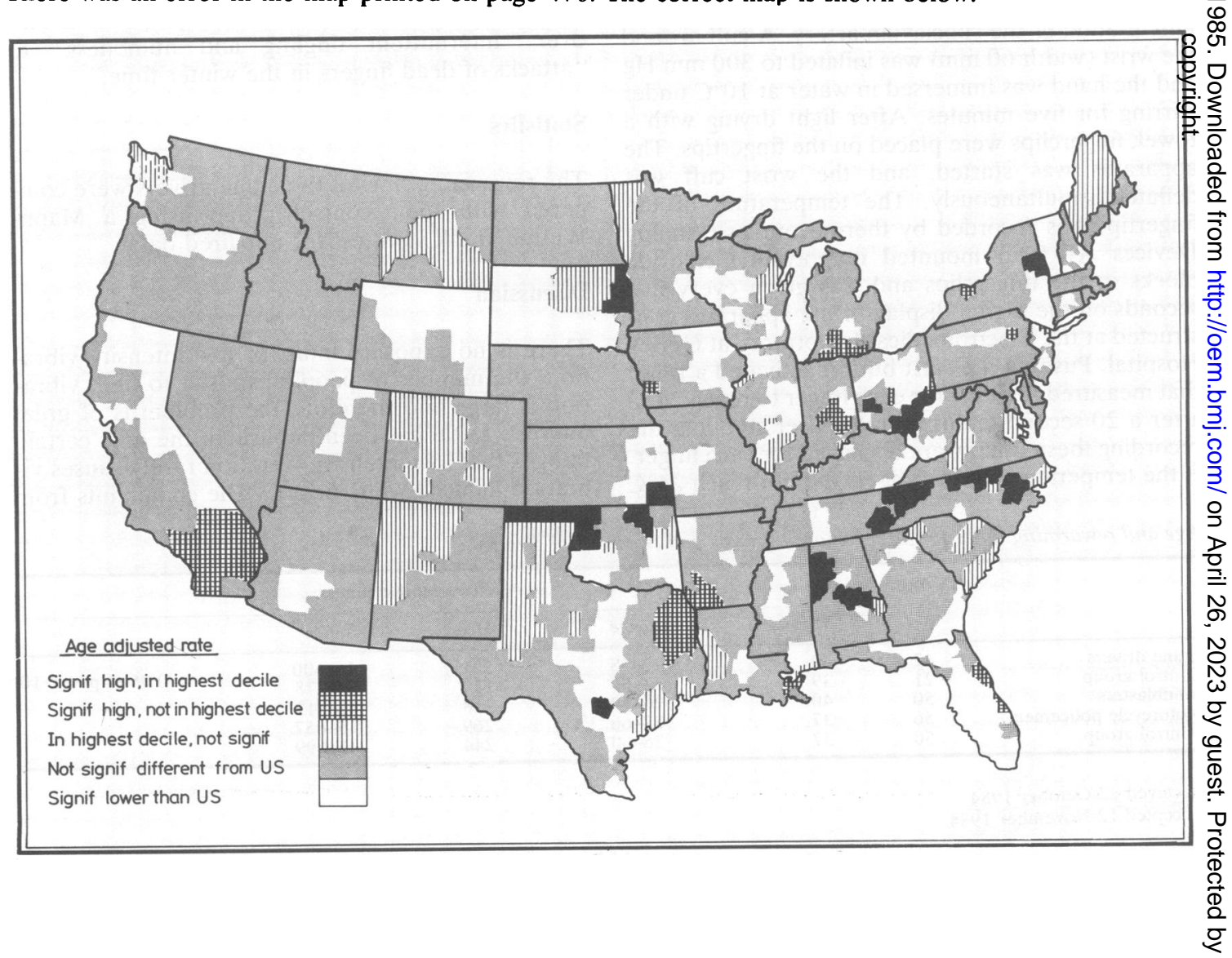

